\title{
LA HERIDA RACIAL EN FRANCISCO MOSCOSO PUELLO: LA ANGUSTIA DEL MULATO
}

\author{
The racial wound in Francisco Moscoso Puello: \\ the anguish of the mulatto
}

\section{Roque Diomedes Santos Cueto}

Profesor e investigador del área de Filosofía y Humanidades de la Universidad Autónoma de Santo Domingo (UASD). ORCID: 0000-0001-6595-1892, Correo-e: rsantos30@uasd.edu.do, santos_roque@hotmail.com

Recibido: 19/01/2021 A Aprobado: 17/02/2021

Cómo citar: Santos Cueto, R. D. (2021). La herida racial en Francisco Moscoso Puello: la angustia del mulato. Ciencia y Sociedad, 46(1), 57-70. https://doi.org/10.22206/cys.2021.v46i1.pp57-70

\section{Resumen}

Francisco Moscoso Puello (1885-1959) es un notable médico dominicano de la primera mitad del siglo xx. Hijo de migrante español y negra dominicana, escribió una serie de obras que influyeron en su momento a la sociedad letrada de Santo Domingo. Cultivador de diversos géneros, su práctica de escritura estuvo permeada por la búsqueda incesante de lo que llamó el alma o el carácter nacional del pueblo dominicano. Regularmente se le coloca dentro del pesimismo dominicano, corriente de pensamiento decimonónica que miró con desdén nuestra composición social y/o racial. En este caso, quien escribe es un mulato que reconoce la composición demográfica de este mestizaje entre blanco español y negra africana; pero su ideal de civilización es la blanquitud europea como la entiende Bolívar Echeverría. A partir del método hermenéutico ideado por Stephen M. North y aplicado a un corpus literario importante, se resume en este trabajo lo que hemos llamado la conciencia escindida o la angustia del mulato. Encontramos que, influenciado por el determinismo geográfico y racial propio a las ciencias sociales del siglo XIX, Moscoso Puello realizó una práctica escrituraria con la intención de sobrellevar la angustia existencial de ser un mulato en un país mulato; aunque no como todos los mulatos dominicanos

\section{Abstract}

Francisco Moscoso Puello (1885-1959) is a notable Dominican doctor of the first half of the 20th century. The son of a Spanish migrant and a Dominican black woman, he wrote a series of works that influenced the legal society of Santo Domingo at the time. A cultivator of various genres, his writing practice was permeated by the incessant search for what he called the soul or the national character of the Dominican people. He is regularly placed within the Dominican pessimism, a nineteenth-century current of thought that viewed our social and / or racial composition with disdain. In this case, the writer is a mulatto who recognizes the demographic composition of this mix between white Spanish and black African; but his ideal of civilization is European whiteness as Bolívar Echeverría understands it. Based on the hermeneutical method devised by Stephen M. North and applied to an important literary corpus, this work summarizes what we have called the split conscience or the anguish of the mulatto. We found that, influenced by the geographic and racial determinism typical of the 19th century social sciences, Moscoso Puello carried out a writing practice with the intention of coping with the existential anguish of being a mulatto in a mulatto country; although not like all Dominican mulattoes given 
dado su acercamiento privilegiado con el mundo europeo a través de su formación académica.

Palabras clave: identidad cultural; determinismo; mulato; blanquitud; civilización; raza.

\section{Introducción}

El mulataje es un tema poco esclarecido en el ambiente intelectual dominicano. Por lo regular se prefiere hablar de las herencias africanas o, en su defecto, de la herencia negra en nuestro folclore o de los discursos hispanófilos de nuestros pensadores decimonónicos y la recuperación que hizo el régimen trujillista (1930-1961) de esta ideología. Esta carencia al abordar el tema no se explica si entendemos que, desde el siglo XVIII, el mulato ha predominado en la demografía nacional (Franco, 2012, p. 122). Resulta extraño que, aunque la élite intelectual dominicana ha invisibilizado la cuestión racial y "el rasero de la raza" cobró notable importancia en la ensayística dominicana del siglo XIX y principios del xx (Rodríguez, 2004, p. 475), el tema del hibridismo del mulato no ha despertado una conciencia nacional capaz de generar identidades alternativas a través de lo que podríamos llamar una conciencia mulata. Abordar la cuestión racial en el país no es solo trabajar la invisibilización de los negros o los aportes de la africanía a nuestra cultura, sino también el análisis sobre la nación en términos de predominio demográfico del mulato y las incidencias en su constitución cultural de la mezcla racial (Andújar Persinal, 2020, p. 46).

La bibliografía sobre el tema negro y los aportes de la cultura africana al país tiene sus textos de obligada consulta: Hugo Tolentino Dipp con su Raza e historia en Santo Domingo. Los orígenes del prejuicio racial en América (1974); Carlos Esteban Deive con su Vudú y Magia en Santo Domingo (1976) o la obra de Franklin Franco Los negros y los mulatos y la nación dominicana (1970), entre otros escritos más their privileged approach to the European world through their academic training.

Keywords: Cultural identity; determinism; mulatto; whiteness; civilization; race.

recientes y de notable importancia (Silvio TorresSaillant, Chiqui Vicioso, Carlos Andújar Persinal). A pesar de que el racismo hispanófilo y el antihaitianismo como ideología predominante en la construcción de la identidad nacional generan debates en los estudiosos de la cultura y la construcción de las identidades dominicanas, no es mucho lo que se pueda encontrar en la actualidad sobre el mulataje y una conciencia mulata en el país. Si adoptamos como verdad de hecho que somos un país demográficamente mulato es poco lo que se ha hablado del mulataje como proceso y como cultura.

A inicios del siglo xx, en plena ocupación norteamericana, Federico García Godoy escribe El derrumbe (1916). El texto fue censurado y no volvió a publicarse hasta 1974. A pesar de la censura, circularon sus ideas en torno al mulataje o el hibridismo étnico como causa de nuestras deficiencias como nación. $\mathrm{Al}$ respecto, el inicio de la obra se expresa en estos términos: "En el hibridismo de nuestro origen étnico residen los gérmenes nocivos que, fructificando con el tiempo, han determinado un estado social en gran parte refractario a un desarrollo de civilización efectiva y prolífica” (García Godoy, 2018, p. 35).

Francisco Moscoso Puello (1885-1959), médico cirujano dominicano, vuelve una y otra vez sobre el tema del mulataje en la constitución demográfica del país y su incidencia en lo que denominó el carácter nacional. Rápidamente podemos establecer que este médico dominicano repite con frecuencia la tesis expresada por Federico García Godoy y defendida por Américo Lugo en el marco de la "inviabilidad de la nación dominicana” (Mateo, 1993, p. 75). Esta tesis es probable que haya tenido la influencia directa del 
positivismo de Eugenio María de Hostos y se remonte a Domingo Faustino Sarmiento en sus señalamientos sobre la civilización y barbarie en Facundo y, sobre todo, en su análisis sobre el conflicto y la armonía de las razas (2007, pp. 19-37).

Después de la primera mitad del siglo xx, la obra capital sobre el mulataje es la monografía de Pedro Andrés Pérez Cabral, La Comunidad Mulata (1967). En ella el autor corrige el argumento de Jorge Amado de que Brasil constituye la única nación mulata en el mundo. Para el autor dominicano exiliado y radicado en Venezuela, ese privilegio le corresponde a la República Dominicana (1976, p. 6). Esta obra, a juicio de Miguel de Mena, critica los problemas de autopercepción del dominicano que ha creado una imagen alejada de su realidad histórica y "sostiene la tesis de que la dominicanidad se sustenta en el mulataje" (2007, párr. 17). Esta visión positiva del mulataje dominicano contrasta con la visión reinante de la intelectualidad criolla y, sobre todo, con la postura adoptada por Francisco Moscoso Puello en sus obras literarias, siendo este último consciente de que era un mulato.

Nuestro interés en este trabajo es abordar la cuestión del mulataje en Francisco Eugenio Moscoso Puello, considerado por muchos como la continuidad del pesimismo decimonónico dominicano cuyo eje central era la "inviabilidad de la nación dominicana" (Mateo, 1993, p. 75). Lo haremos a partir de lo que hemos denominado "la angustia del mulato" ya que nos deja perplejo la ambigüedad con que aborda el mulataje, tanto en su persona como en la sociedad dominicana. Hemos seleccionado este autor porque no es un blanco que escribe sobre las razas, hasta ese momento, consideradas como inferiores; sino que es un mulato que escribe sobre el país y sobre sí mismo a partir de las ideas expuestas por la élite blanca sobre el hibridismo étnico de la nación. Por otro lado, el mulataje, nos parece, fue medular en su pensamiento y se le ha abordado muy poco en los estudios literarios y culturales en el país desde la perspectiva en que la trató en sus obras literarias: como un problema existencial de búsqueda de sí a través del análisis y la reflexión sobre el alma o el carácter nacional.

En esta psicología social del alma dominicana realizado por el médico y un hombre de letras, encontramos un perfecto ejemplo de lo que el pensador francés Paul Ricoeur llamó "identidad narrativa” y de una de las tesis centrales del hermeneuta francés de que no hay un acceso inmediato a la conciencia, sino el mediado por el lenguaje en la dialéctica entre la reflexividad y el análisis (Ricoeur, 1996a).

Nos preguntamos en qué medida la búsqueda del alma dominicana o el carácter nacional estuvo permeada por la búsqueda de sí mismo como mulato dominicano y su diferenciación racial respecto al blanco y al negro. En la búsqueda de respuestas en la obra literaria del autor, nos mueve la convicción de que en Moscoso Puello la representación o configuración de sí fue posible a partir de la narración de una vida dentro de su temporalidad y su historicidad, es decir, mediante la función narrativa (Ricoeur, 1999, p. 215). En este sentido, hubo una búsqueda de sí que se inserta en la búsqueda del carácter colectivo nacional; hecha bajo un mismo discurso, pero expuesta en textos, géneros $\mathrm{y}$ contextos diferentes.

\section{El método hermenéutico}

Cuando hablamos de autores fallecidos e intentamos descubrir sus huellas en sus textos, la labor de comprensión de estos va aparejada por una interpretación del horizonte cultural que permitió su génesis, los recursos teóricos y formales utilizados en su comunicación, la cosmovisión que predomina en la "cosa" o el "mundo del texto" y, por último, el componente del mundo de la vida que corresponde, aunque diferenciados, tanto al autor como al lector (Ricoeur, 1996b, p. 864). En cada lectura hay un pretexto o prefiguración, una configuración y, posteriormente, una refiguración que 
es traer el texto a la vida; el texto parte de la vida y vuelve a la vida (Ricoeur, 1987, p. 152).

Estas teorías hermenéuticas de Paul Ricoeur son un bagaje conceptual muy amplio que necesita materializarse en pasos concretos para la indagación e interpretación de la cultura a través de los textos y sus autores. Aunque debemos señalar que, después del estructuralismo y la muerte del autor (Barthes, Foucault, etc.), el lector está solo frente al texto y debe partir de este para interpretarse a sí mismo y ser transformado por la lectura. Pero no nos enfoquemos en la lectura, hagamos el proceso inverso, enfocarnos en la práctica escrituraria, para comprender y explicar (interpretar) lo mejor posible no solo la cosa del texto, lo que se ofrece al lector, sino también las huellas del autor en los textos (Certeau, 2000, p. 147). No con la pretensión diltheana de comprenderlo mejor que a sí mismo (Ricoeur, 2002, p. 82), sino para, precisamente, interpretarlo en sus preocupaciones, creencias, cosmovisiones, angustias existenciales o lo que, parafraseando a Ernesto Sábato, podemos llamar "sus fantasmas" que, para nosotros, en la obra de Moscoso Puello se reducen al lugar del mulataje en el futuro y la psicología del dominicano.

Hermenéutica es interpretación y no era solo un ámbito de la lectura, sino de la comunicación de lo pensado a un lenguaje comprensible (bien sea de modo oral o escrito) que permite comunicar una experiencia de vida bajo las premisas dadas en el mundo de la vida (Santos Cueto, 2017, p. 49). Amparado en esta larga tradición de la hermenéutica filosófica se plantea el método hermenéutico o la interpretación a partir de los mismos textos y no bajo el influjo de una aplicación de esquemas previos a estos.

A conveniencia y grosso modo, en lo adelante se seguirá el método hermenéutico propuesto por Stephen M. North en su artículo "Writing in a Philosophy Class: Three Case Studies" (1978/1986) y retrabajado por Ángel F. Sánchez Escobar (2001). North construye el método para el análisis cualitativo de la escritura y establece tres etapas y dos niveles con una serie de contextos interpretativos (North, 1986, p. 225). Sánchez Escobar lo reduce y lo viabiliza a la interpretación de lo que llama un "canon" y que denominamos corpus.

Si adaptamos la propuesta original de North, inspirados por las transformaciones que realiza Sánchez Escobar, podemos establecer nuestro esquema que sería el siguiente: el primer nivel es empírico y estaría compuesto por la primera etapa que reside en la elección del corpus para analizar; es decir, la elección del conjunto de obras base para la investigación (Pitkowski y Gamarra, 2009, p. 33). El segundo nivel, denominado interpretativo, consistiría en la aplicación de la segunda y tercera etapa. La segunda etapa sería el análisis y la interpretación de los textos; allí se buscan las pautas de los textos y se intenta explicarlas. Por último, la tercera etapa, radica en la generación de teorías a partir de lo encontrado en las etapas anteriores (Sánchez Escobar, 2001, p. 301). El método elegido nos permite dar cuenta de los textos y sus rasgos para, desde ellos, describir el discurso a partir de las repeticiones alrededor de nuestra temática eje, el mulataje, y algunos conceptos afines.

\section{Primera etapa: el corpus}

El corpus para análisis estará compuesto por cuatro obras literarias de Francisco Eugenio Moscoso Puello. En orden cronológico, Cartas a Evelina es una colección de cartas publicadas en Cunas de América (1913) y en el Listín Diario (1930-1935). Esta obra es considerada como un ensayo sociológico sobre el carácter dominicano; a nuestro juicio se trata de una serie de cartas monologales inspiradas en la psicología social francesa y publicadas originalmente bajo el título de IDEAS. La colección se misivas se publicó en 1941 bajo la editorial Montalvo, no tuvo la repercusión esperada hasta 1974 cuando en menos de un año se agotaron dos ediciones. En 1936 publica un artículo de opinión titulado De la Odisea de la Hispa- 
niola. Este artículo es la síntesis de una obra mayor que no escribió, pero que tuvo como proyecto paralelo a Cartas a Evelina. El artículo provocó un revuelo de opiniones en la época hasta el punto de que el encargado de la embajada estadounidense se hizo eco de este en comunicado oficial al gobierno norteamericano. También en 1935 publica la novela Cañas y Bueyes, considerada como una de las novelas de caña en donde retrata la vida alrededor de los ingenios azucareros en manos del capital norteamericano. Por último, Navarijo escrita en 1940, pero publicada posteriormente. Es un libro de sus memorias familiares alrededor de la importante figura paterna y el barrio popular que da título a la obra. No tomaremos en cuenta sus obras dedicadas a las ciencias médicas ni sus Apuntes para la historia de la medicina en la isla de Santo Domingo.

\section{Segunda etapa: el análisis y la interpretación de los textos}

\section{La imagen individual ligada a la colectividad}

Las primeras cinco misivas de la obra Cartas a Evelina se escribieron en 1913 en un momento de inestabilidad política y una condición de pobreza heredada desde el siglo XVII. Todavía la adolescente república no encontraba su camino hacia el progreso material y espiritual de todos sus miembros. La intelectualidad agotada y frustrada de la política, de las revueltas militaristas y de la clase gobernante. Bajo este contexto inicia Moscoso Puello su labor de escritura y análisis sobre el alma dominicana o el carácter nacional, conceptos estos referidos para hablar de lo que luego se entenderá como identidad colectiva o identidad nacional cultural. A partir de esta crisis de identidad colectiva es natural que la intelectualidad se aventure a la pregunta existencial sobre el quién soy, enmarcada dentro de este contexto nacional.

Se supone que, según la nota aclaratoria al libro, Cartas a Evelina es una obra de psicología social que describiría el carácter del dominicano; pero el inicio de la primera carta está cargado de notas autobiográficas que revelan una reflexión sobre sí mismo, sobre su individualidad, más que sobre la colectividad. Transcribo las primeras líneas:

Señora: ¡Yo he cambiado mucho! De pocos años a esta parte soy otro, es decir, soy el mismo en otro. Esto no tiene nada de particular si usted tiene en cuenta de que no he hecho otra cosa que no sea obedecer a la más general de todas las leyes de la naturaleza. (Moscoso Puello, 2000, p. 7)

El tono de las opiniones sobre el alma dominicana se verá marcado por este carácter angustioso de búsqueda de sí (el yo identitario) desde la perspectiva de las leyes naturales, como algo irrevocable en el tiempo. Este ser "el mismo en otro" es una muestra de la simultaneidad en el sujeto del cambio y la permanencia. Algo ha cambiado y algo sigue siendo lo mismo en este individuo que se denomina de entrada solo como "yo". La representación de sí es la del quién subyugado a la ley natural, a este quién (identidad personal) que habla en la escritura solo le resta obedecer lo que es tenido como necesidad natural. Esto último nos indica de inmediato el gran peso que tendrán los determinismos en esta obra.

En la carta literaria lo estético se supedita a lo discursivo. Lo importante no es la producción de una obra bella, en términos de formalidades estéticas y en donde se margina lo didáctico (Beltrán Almería, 1996, p. 245), sino la construcción de un discurso marcado por un carácter existencial porque se intenta encontrarle un sentido a la vida en esa toma de conciencia del mundo, de los otros y de sí mismo (Fernández, 2018, p. 28). Por ello el cierre hermenéutico entre Cartas a Evelina y Navarijo, que es su texto más autobiográfico y en el que hace memoria sobre su niñez en el populoso barrio de la ciudad capital del siglo XIX y principios del siguiente. Las dos obras de 1936 se constituirían en la indagación menos subjetivas del corpus señalado, ya que 
están enfocadas en la cuestión racial como centro del alma dominicana, De la Odisea de la Hispaniola y, como caso de relación polarizada entre propietarios y proletarios, Cañas y Bueyes.

La labor de escritura en Moscoso Puello no es por simple pasión estética, sino por la indagación existencial de búsqueda de sí en tanto que sujeto individual, pero también como colectividad enmarcada en un espacio geográfico, cuya fuerza es determinante y no tan solo una condición. El inicio de Navarijo está marcado por la memoria del mito romántico del pasado feliz: "Aquellos eran otros tiempos" (Moscoso Puello, 2015, p. 35). A pesar de que retrata la ciudad de aquellos tiempos con la ciudad del presente en el que vive, la memoria está enfocada en las vivencias del quién del discurso mediatizado por el yo: "El Santo Domingo de Guzman en que yo vine al mundo era otra ciudad, muy diferente de esta en que yo estoy viviendo ahora" $(2015$, p. 35$)$. Al final de la obra, nos reitera lo mismo en un círculo de pesadumbre existencial entre el individuo y la ciudad, el eterno retorno (2015, p. 457).

La identidad del quién o el "yo" discursivo en ambos textos nos mostrará la identidad del personaje que reflexiona y se comprende a sí mismo mediado por el análisis. Esto es, como señala Paul Ricoeur, porque no hay un acceso inmediato a la conciencia, sino el mediado por el lenguaje a través de las dialécticas entre la reflexión y el análisis (Ricoeur, 1996a, p. 112).

Rápidamente notamos que, entre otras preocupaciones de índole sociohistóricas, el "yo" enunciador que se describe en Cartas a Evelina y Navarijo está atravesado por la misma preocupación: el color de su piel. El 26 de marzo de 1885 nace Moscoso Puello. Hijo de padre español y una negra dominicana de Baní a quien él atribuye sus mejores dotes intelectuales. A los ojos del adulto que recuerda y reflexiona sobre el pasado las dos mujeres que representaron ternura en su infancia, su madre y su tía Mariquita, son las que colocan la herida racial en el niño. La tía Mariquita es la que primero ofende al niño al considerarlo el más oscuro de la familia (Moscoso Puello, 2015 , p. 152), por tanto, el más feo de los sobrinos, el que se había dañado en su aspecto visible. Por otro lado, su madre es quien lo presenta como "la surrapa", el último de los vástagos, el "prietico de aquî" o "las borras de café" haciendo mención del color de piel.

La conciencia de esta preocupación por lo racial se esclarece en los siguientes términos:

Sin embargo, yo estoy convencido de que no he cambiado mucho. De todos mis hermanos he sido el más feo y el más prieto. La raza africana de mis ascendientes me tocó a mí en mayor cantidad que a los otros. De acuerdo con la Ley de Mendel yo pertenezco a un cuarto de la segunda generación filial. (Moscoso Puello, 2015, p. 192)

El negrito de la casa en un país de familia multicolor, según la expresión de Arthur J. Burks en 1936, es un rasgo distintivo que no solo declara el color de la piel, sino que trae consigo un juicio estético sobre su persona que muestra la preocupación por estos aspectos raciales. La permanencia del color de la piel y de los atributos estéticos invariables están connotados a través del "no cambio" en vista de que se está bajo el poder de la ley natural. Esta es la conciencia de sí en términos étnicos y esta es la gran preocupación del adulto que mira en su niñez el origen traumático de su condición racial: "No podía sospechar a los cuatro ańos que esto sería, con el tiempo, mi mayor preocupación" (2015, p. 192).

En la carta número doce de Cartas a Evelina se repite esta conciencia escindida racialmente en términos de "división de castas" y de pureza de sangre:

Tengo un ochenta por ciento de blanco, soy un mestizo de tres cuartos de sangre, es decir, más blanco que negro, por lo cual puedo desarmar 
un reloj, bregar con tomillos [...] y hacer otras cosas por el estilo que, indiscutiblemente, sólo pueden hacerlas bien hechas los blancos puros, $\mathrm{y}$ por eso en New York me he sentido como en mi propia casa. (Moscoso Puello, 2000, p. 72)

Aquí la noción de mestizaje es la mezcla, sin importar la raza, como lo veremos en su artículo de opinión de 1936. En este sentido, el mulato es producto del mestizaje o mezcla entre razas, un híbrido en los términos de Federico García Godoy en El derrumbe. Como vemos, la oposición entre civilización y barbarie (Domingo Faustino Sarmiento) se conjuga con la oposición entre blanco y negro. En este caso, la blanquitud o el acercamiento hacia los rasgos blancos determinan el grado civilizatorio expresado en los elementos propios de la modernidad norteamericana (García García, 2012, p. 65). En este fragmento de Cartas a Evelina, lo racial es biológico y este se confunde arbitrariamente con lo cultural (Valderrama, 1986, p. 89), un elemento central en el determinismo racial del siglo xIX que tuvo como ideología el paradigma positivista de corte darwinista-spenceriano en su visión de la sociedad como un ente vivo sujeto a leyes irrefutables (Tinoco Guerra, 2017, p. 147).

En el artículo de opinión De la Odisea de la Hispaniola, el mestizaje es lo que constituye el mayor problema del carácter nacional en vista de que solo las razas puras (blancos o negros puros) son las que han constituidos una verdadera unidad nacional (Moscoso Puello, 1936). La unidad racial es la que permite la unidad de la nación, de ahí el contraste con la República de Haití en donde, a juicio del autor, hay una unidad racial mayor que la que impera en el nuestro.

Desde el siglo Xvir, según lo muestran los estudios sobre la composición demográfica del país, hay una constante mulatización, a pesar de las restricciones y disposiciones en su contra de parte de las autoridades coloniales (Franco, 2012, p. 100). El siglo
XVIII es plenamente el siglo de la composición social mulata de la parte oriental de la isla y el predominio de la raza negra esclavizada en la parte occidental. El siglo XIX es la constitución de dos repúblicas distintas en la isla La Hispaniola, latinización del término La Española. Por esta razón es que Moscoso Puello realiza el contraste racial entre ambos partes de la isla.

En el caso de la República de Haití nos dice que "la raza negra es la que le ha dado fisionomía e interés"; en cambio, en nuestra República lo que prevalece es "la falta de homogeneidad racial y por consiguiente espiritual” (Moscoso Puello, 1936, párr. 9).

El censo que le sirve de referencia es el primer censo dominicano de 1920, en donde la composición demográfica reveló que, de un poco más de ochocientos mil habitantes, más de la mitad eran mulatos y el resto de la población se repartía en proporciones iguales entre blancos y negros. A partir de este dato sostiene que: "Puede decirse que la República de Haití ha constituido siempre un Estado negro, en cambio Santo Domingo lo ha sido siempre mulato. Los negros han carecido aquí de personalidad y no han tenido representativos" (1936, párr. 12).

Amparado en el determinismo biológico establece que la historia del país ha sido nuestra historia biológica de predominio de una raza híbrida, sin uniformidad racial. El fatalismo está en que estas luchas de fuerzas, siguiendo los planteamientos de Gobineau y otros pensadores franceses de finales del XIX $\mathrm{y}$ primeras décadas del $\mathrm{xx}$, no permite la unidad nacional, lo que nos constituye en "un mosaico físico y espiritual” (1936, párr. 17) o simplemente en un "conglomerado", pero no en una comunidad política o nación.

Contrario a los planteamientos de Bonó que veía en el dominicano una disposición hacia la civilización dada por esta relajación en la mezcla racial (Bonó, 2007, p. 135), Moscoso Puello se decanta por la 
visión negativa del nosotros respecto a su contenido racial o biológico. En el médico dominicano, la mezcla es deficiencia constitutiva del carácter nacional que no permite el avance en términos de modernidad europea y norteamericana:

Desde el punto de vista racial, hay una lucha dada y callada que es la causa de la falta de unidad de acción, de la unidad de pensamiento, de la unidad de ideal que es la característica del pueblo dominicano. Aquí nadie está de acuerdo con nadie, ninguna acción común permanente puede ser realizada por este motivo, no hay solidaridad ni espíritu de asociación. (Moscoso Puello, 1936, párr. 17)

La confirmación de la ley natural en la constitución racial del pueblo dominicano y la irradiación de esta tara biológica a los demás órdenes de la vida social e individual es lo que impide la creación de una conciencia nacional capaz de llevar a la nación por las sendas del progreso. Lo biológico, la tara racial heredada, incide en la colectividad en su falta de intereses comunes y de un sentimiento nacional que construya una nación civilizada:

En Santo Domingo no hay intereses comunes. Nadie se cree ni quiere ser más prieto que los otros. Y todos se consideran blancos. Este estado de espíritu pesa más que ninguna otra causa, es la fuente de las desgracias de este país. Le ha hecho desgraciado su falta de unidad etnológica. Y puesto que las razas puras no existen me refiero al mayor grado de uniformidad física y espiritual que como razas consideramos y definimos. (Moscoso Puello, 1936, párr. 18)

Este estado de espíritu en el que se es una cosa y se cree otra es lo que he denominado la herida racial o la agonía del mulato. Herida que nos viene de lejos y que está matizada por las vivencias peculiares del sistema colonial en nuestro territorio y por los mecanismos de movilidad social durante la colonia
(Franco, 2001, p. 19). Recordemos la postura de los "blancos de la tierra", aquellos negros o mulatos que pretendían diferenciarse de todo lo que representaba el sistema esclavista asimilándose al canon blanco en términos simbólicos (Silié, 1989, p. 3). Por otro lado, miremos también el problema de la conciencia nacional en la formación de la nación, construida a base de una invisibilización de los aportes negros a la cultura dominicana.

La negación del componente negro y la aproximación a lo blanco son muestras de una conciencia escindida y angustiada que construye una inferioridad respecto al extranjero civilizado. Esta polarización racial entre blancos y negros es expuesta en un caso concreto en Navarijo y también en las denominaciones de ambos grupos, tanto en Cartas a Evelina como en Cañas y Bueyes. Para muestra un botón de esta herida racial en el pueblo dominicano: en Navarijo, cuenta Moscoso lo sucedido con el zapatero Blas a quien su madre, negra, había obligado a separarse del amor de su vida, una joven esposa también negra, con las siguientes palabras: "-No es posible - le dijo un día- que yo me sacrificara con un hombre a quien no quise nunca, solo para adelantar la casta y que tú vuelvas a saltar para atrás" (Moscoso Puello, 2015, p. 347). Blas era lo que se llama un "mulato y pobre" que "en Santo Domingo es la peor de las desgracias" (2015, p. 348).

El mulato de Santo Domingo, en los términos en que se refiere Moscoso Puello, es un individuo escindido por la raza y por el clima tropical que anhela blanquecerse, sino en su piel al menos en sus comportamientos, presencia y apariencia frente al otro. De ahí que la elección de la pareja debía obedecer al blanqueamiento de la raza, para no "saltar para atrás" en la jerarquización y diferenciación racial. El determinismo geográfico, que proviene de la antigüedad clásica occidental, es conjugado con el determinismo biológico del siglo XIX como causa explicativa de la inviabilidad de la nación dominicana al que se le ańade el hibridismo étnico y cultural de la 
población. En Cartas a Evelina el autor nos habla del "mulato tropical" como un tipo especial dentro de la mezcla racial de las américas (Moscoso Puello, 2000, p. 14).

A juicio de Moscoso Puello, el mulato dominicano puede ser esa raza cósmica de Vasconcelos (Moscoso Puello, 2000, p. 189), pero también puede ser el "intermediario" necesario que requiere el explotador extranjero blanco (2000, p. 79) o el mulato que nos dio la independencia en 1844, refiriéndose a Mella y a los generales mulatos del proceso independentista, o el que nos pone en cintura cuando llega al poder, refiriéndose a Báez y a Lilís (2000, p. 189).

En definitiva, Moscoso Puello concluye que somos un pueblo mulato que se diferencia de los negros haitianos y que no se piensa a sí mismo como negro porque lo negro ha sido una fuerza minoritaria, sin representación dentro de la cultura (Moscoso Puello, 1936, p. 12).

\section{El otro del nosotros: el extranjero, los cocolos y los haitianos}

Si en Cartas a Evelina el extranjero es básicamente el blanco civilizado, aquel que porta los grados de civilización y el capital, es igualmente el que explota nuestro suelo, el dueño de los comercios y las escasas industrias del país (Moscoso Puello, 2000, p. 77). Lo mismo sucede en Cañas y Bueyes. En esta novela de la caña, el extranjero es referido como el "blanco", el brasero haitiano es el "negro" y la mano de obra extranjera y negra son los "cocolos". Por ejemplo, don Marcial es un colono dominicano que se arriesgó al cultivo de la cańa para el ingenio que administraba el Señor Moore. A causa de las decisiones del yanqui, don Marcial cae en la miseria, pero contempla desde su posición aristocrática de propietario a los dominicanos que dependen de su trabajo y a los haitianos explotados como "infelices"; el narrador omnisciente describe su pensamiento cuando termina de contemplar cómo ha caído en el engaño del Señor Moore (apelativo siempre en mayúsculas en la obra): "A menudo recordaba don Marcial las palabras de Uribe: ‘ Estos blancos saben mucho'!” (Moscoso Puello, 2004, p. 70). Los blancos del batey son los que ocasionan las injusticias que emanan de la condición de trabajo y son los que hablan mal de los dominicanos (2004, pp. 178-179).

La blanqueación constituye el baremo del poder y la civilización aún en los personajes que, por su condición, deben adoptar una postura más crítica o subversiva hacia el amo blanco. En la novela Cañas y Bueyes dos obreros tienen desavenencias y uno de ellos exclama que "Los dos eran prietos según él. Y esa era la suerte, porque si Gautier Mojica fuera más clarito, quién lo iba a aguantar. Si con ser así, tan oscuro, es más déspota que los mismos blancos, se la daba más" (Moscoso Puello, 2004, p. 155). Al final de la cita vemos cómo el subyugado se convierte en victimario de los demás y como el color de la piel es metonimia del poder en cuanto que determina la posición en la relación jerárquica.

Los cocolos son la mano de obra experimentada que vino de las Antillas menores a la industria azucarera dominicana, son negros no hispanos que en la obra de Moscoso Puello están caracterizados de forma distinta de los haitianos. Regularmente eran obreros especializados que hablaban en inglés, lo que les daba un poder sobre los demás obreros y la oportunidad de salirse con algunas ganancias dentro del esquema laboral del ingenio (2004, p. 89). Es muy fácil establecer en esta novela que en la escala social más baja estaba el negro haitiano, quien venía huyéndole a la miseria en su país. Uno es "cocolo" y el otro es el haitiano. Aunque los dos son extranjeros y negros, en la novela, aunque no pertenecen a la categoría privilegiada de propietarios, sino todo lo contrario, tienen un tratamiento racial distinto en la diferenciación con el dominicano (2004, p. 177). 


\section{Tercera etapa: la generación de teorías}

En la generación de teorías, a partir de lo encontrado en los textos, debemos distinguir la blanqueación del poder y la propiedad, como aparece en Cañas y Bueyes y Navarijo, de lo que el filósofo ecuatoriano Bolívar Echeverría llama propiamente blanquitud, como aparece en Cartas a Evelina y De la Odisea de la Hispaniola. En este autor ecuatoriano-mexicano la blanquitud está ligada a la modernidad, pero tiene una dimensión europea en la que la identidad se liga al desarrollo económico, por lo que hay una "blancura" racial y cultural de las masas trabajadoras; luego hay una modernidad americana que muestra una continuidad capitalista, pero rebaza los contornos geográficos de Europa y se centra en la producción para el consumo (Echeverría, 2007, párr. 9).

A pesar de que Echeverría aclara más tarde que la imagen de blanquitud reconstruida obedece más a una cuestión de civilización y no de color de piel, ello no impide que encontremos trazos de esta blanquitud racial y cultural en las obras de Moscoso Puello. En este sentido, la blanqueación del poder es un reflejo de la blanquitud de las masas en la medida en que ocurre lo que Gonzalo Portocarrero señala como "utopía del blanqueamiento", es decir, la colonización del imaginario del mestizo, en nuestro caso, del mulato (2013, p. 176).

La agonía del mulato que hemos descrito en los textos de Moscoso Puello es el producto de esta combinatoria entre un imaginario civilizatorio de modernidad ligado a la blanquitud, tenida siempre como ideal que alcanzar, y la concreción de lo real o la facticidad de un color de piel, prueba irrefutable del mestizaje entre el amo blanco y la negra esclavizada. El conflicto permanente entre los rasgos civilizatorios blancos y el color de piel morena (prieta, fea; aunque nunca considerada como negra) muestra una identidad escindida en la medida en que no se asume como algo nuevo, sino como algo que hay que "mejorar" o "regenerar" por asimilación y diferenciación.
En Moscoso Puello, la dialéctica de la reflexión sobre el sí colectivo (el carácter nacional o la identidad colectiva como dominicano mulato y tropical) y la que hace sobre el sí individual (la identidad personal como mulato del trópico) se hace a través del análisis biologicista de la raza acompañado de un determinismo geográfico. Este marco teórico surgió durante el siglo XIX, de la mano de las teorías evolucionistas aplicadas a las ciencias sociales, con el fin de establecer lo que se llamó "el espíritu de los pueblos"; pero, igualmente, trajo oculta la intención de justificar la jerarquización de los pueblos "civilizados" (blancos) sobre otros no civilizados (negros). La gran paradoja es que no solo la élite criolla echó mano de estas ideologías para explicar la situación de debilidad e inestabilidad política de las naciones después del proceso independentista; sino que la abrazaron $\mathrm{y}$ continuaron en sus escritos pensadores que provenían de hogares híbridos racialmente, como es el caso de Moscoso Puello. Por lo regular, la postura que adoptan frente al hibridismo es negativa y proyectan como carencia, en el otro imaginado, lo que pretenden haber superado por asimilación a la civilización blanca, siempre tenida como baremo de diferenciación y jerarquización social.

El quién que se representa en este corpus literario analizado es un mulato que se ve a sí mismo desde una angustia existencial insalvable porque está sujeto al devenir necesario de las leyes naturales, pero, por su componente sanguíneo-cultural predominante se asume como más cercano al otro-blanco que al otro-negro. La identificación con el blanco civilizado, siendo mulato, es también la negación del otro no civilizado, lo negro, que forma parte de lo propio. La herida racial o lo que he denominado de angustia del mulato es un fenómeno que muestra un sujeto escindido por la utopía del blanqueamiento y la realidad de un entorno demográfico y racial que le es adverso.

La mirada fatalista que se genera a partir de los determinismos geográficos y biológicos coloca la cuestión racial en el centro de los procesos identitarios tanto 
de la colectividad como del individuo. La identidad narrativa generada a partir de esta utopía del blanqueamiento está atravesada por la ambigüedad en la relación con la alteridad. Se niega para el otro lo que se ha adquirido para sí o bien no se asume para sí lo que se le atribuye al otro. La identidad personal y colectiva resultante es una identidad agónica por el juego entre carencia y presencia. Se desea lo que visiblemente no se obtiene, la blancura de la piel, y se magnifica en sí la presencia de lo que representa lo que visiblemente no se obtiene, es decir, la cultura o la inmaterialidad de las habilidades que se imagina como ideal civilizatoria, como utopía. La angustia que deja la herida racial en un mulato que no asume el mulataje como una nueva realidad, sino como una tara, se resuelve a través de la "pose" que brinda la cultura. Ocurre, pretendidamente en un plano más elevado cultural y socialmente, lo que los "blancos de la tierra" procuraban: alejarse, a través de la exageración de la apariencia, de los otros iguales que todavía permanecían bajo el yugo del amo en el sistema colonial.

La utopía del blanqueamiento es la contraparte de una conciencia escindida por la herida racial que deja la experiencia del mulataje en el país y los discursos construidos sobre la identidad dominicana como blanca y no negra. Permanecer en la oposición entre lo blanco y lo negro es olvidar lo que se ha generado en el país y que, probablemente, sea lo más autóctono: el mulataje. El problema es la carga negativa del concepto mulato, en tanto que hibridismo, que no la conserva el vocablo mestizaje. La carencia de una conciencia del mestizaje/mulataje como un elemento de primer orden en la construcción de las identidades nacionales y personales es un hecho que demanda una nueva reflexión y análisis.

\section{Conclusión}

Francisco Moscoso Puello tuvo una vida dedicada a las ciencias y a las letras, como él refería. Sus escritos literarios están marcados por esta búsqueda sobre lo que en su momento se llamó el alma o el carácter nacional; esto es, la constitución sustancial de unos rasgos permanentes tanto en la colectividad como en los individuos. Estos rasgos pensó encontrarlos en la composición biológica de la nación, es decir, la raza. Inspirado en el racismo científico del siglo XIx, analiza la composición racial del pueblo dominicano, de mayoría mulata, como una tara que imposibilitaba la unidad de la nación dominicana. Ahora bien, a su juicio, como en el origen racial del mulato está la mezcla o el hibridismo de dos razas antagónicas, lo que ha hecho el trópico es equilibrar las fuerzas opuestas entre las razas. Este equilibrio no es generador de nación en vista de que en la arquitectura del poder racial debe haber un desequilibrio de sus fuerzas: o se es blanco puro o se es negro puro; solo así se construye una unidad.

Analizar la obra literaria de Moscoso Puello a partir del método hermenéutico propuesto por North nos ha permitido ver sus obras literarias como un corpus ideológicamente relacionado, en el que se muestra a un mulato angustiado por su condición y que ve en la colectividad las consecuencias negativas del hibridismo racial; aunque no en su persona. Estas breves notas sobre el mulataje y la raza en un autor importante para la primera mitad del siglo xx muestran cómo la conciencia mulata no ha sido una alternativa viable en un país que tradicionalmente ha negado la negritud como un rasgo constitutivo de su identidad y cuya población es mayoritariamente un híbrido racial y cultural. Por eso el decantarse hacia una hispanidad imaginaria y tradicionalista y no mirar al futuro como una nación con grandes desafíos que requieren el concurso de todos.

El análisis de las obras literarias muestra que en Moscoso Puello no se valora al mulato; no hay una concepción del hibridismo racial como una oportunidad para alcanzar los requisitos del baremo de la civilización blanca europea. Lo que pudo haberse planteado sobre el mestizaje característico, que encarnaría lo mejor de América Latina, se presenta como una debilidad, como una tara infranqueable 
del pueblo dominicano por su población mayoritariamente mulata. A pesar de la constatación de una colectividad predominantemente mulata, esto no constituye en modo alguno una ventaja, sino una deficiencia que impide trazar proyectos comunes como nación y que retrasa el progreso y la mejora de los individuos. ¿Cuál es la solución? No hay otra a no ser la de impregnar de civilización tanto al individuo como a la colectividad. Esta conclusión del autor se afianza en su propia conciencia atormentada por el color de su piel, aunque había alcanzado comportamientos y refinamientos tenidos como blancos o perteneciente al mundo civilizado blanco por su inteligencia privilegiada.

"Los mulatos hemos sufrido y pasado malos ratos" nos dice en la carta número doce de Cartas a Evelina y atestiguará al final de su vida en una obra autobiográfica como Navarijo. Esta figura de sí de Moscoso Puello se construyó sobre la diferenciación racial que estableció el discurso hispanófilo del siglo xIx y al cual da continuidad durante la primera mitad del siglo xx. La conciencia de sí que establece en relación con la colectividad y la construcción de la identidad narrativa se ve herida por la cuestión racial planteada en términos del hibridismo o la mezcla cuyo resultado es deficiente. Esta concepción negativa del mulataje, visto como una tara que no permite la unidad de la nación ni del individuo, es la que atraviesa la conexión entre la teoría y la vida en la persona de Moscoso Puello.

La construcción de la teoría a la que hemos arribado nos señala la necesidad de pensar la conciencia mulata en la nación dominicana, cuestión todavía abierta por la herida racial que ha provocado el discurso antinegro en el país y la predominancia del tema de la herencia africana en los estudios culturales. Todavía la cuestión mulata, el mulataje, queda pendiente de un mayor análisis en el discurso racial dominicano.

Nos hemos inspirado en la obra de Moscoso Puello para estos planteamientos porque es un mulato que no se asume como tal, ya que entendió que el hibridismo racial no permite la unidad del sujeto como tampoco el de la nación. A mi juicio su obra brinda la síntesis final de una larga tradición de prejuicios raciales en textos de gran popularidad en la cultura dominicana y que paradójicamente se reeditan y comentan sin una nota crítica al respecto. Da la impresión de que se pretende dar continuidad a lo que debe quedarse en el pasado como el espíritu de una época a ser superada.

\section{Referencias}

Andújar Persinal, C. (2020). Ideología y afrodescendencia en la República Dominicana. Revista Humanismo y Cambio Social, 6(14), 41-49. Recuperado de https://doi.org/10.5377/hcs. v0i14.9711

Beltrán Almería, L. (1996). Las Estéticas de los géneros epistolares. 1616: Anuario de La Sociedad Espanola de Literatura General y Comparada, 10, 239-246. Recuperado de https://doi.org/10. 15359/rl.2-66.1

Bonó, P. F. (2007). Pedro Francisco Bonó: textos selects. Archivo General de la Nación. Recuperado de http://colecciones.agn.gob.do/opac/ficha. php?informatico $=00087090$ PI $\&$ codopac $=\mathrm{O}$ PPUB\&idpag $=1784244509$

Certeau, M. (2000). La Invención de lo cotidiano. Universidad Iberoamericana. Recuperado de https://circulosemiotico.files.wordpress. com/2012/10/de-certeau-michel-la-invencion-de-lo-cotidiano-1-artes-de-hacer.pdf

Echeverría, B. (2007). Imágenes de la "blanquitud. En D. Lizarazo (Ed.), Sociedades Icónicas. Historia, ideología y cultura en la imagen. Siglo XXI. Recuperado de https://webcache. googleusercontent.com/search?q=cache:HJUWoKhPaLQJ:bolivare.unam.mx/ensayos/ download/imagenes_de_la_blanquitud_/ Bolivar_Echeverria-Imagenes_de_la_blanquitud.pdf $+\& c d=3 \&$ hl $=$ es $-419 \& c t=c \operatorname{lnk} \&-$ $\mathrm{gl}=\mathrm{do} \& \mathrm{client}=\mathrm{avg}$ 
Fernández, E. C. (2018). Las escrituras del yo y sus variantes funcionales. Revista de Filología de La Universidad de La Laguna, 37, 25-39. Recuperado de https://dialnet.unirioja.es/ servlet/articulo?codigo $=6466638$

Franco, F. (2001). Ensayos profanos. Sobre racismo, pesimismo e izquierdismo. Digitalia Publishing. Recuperado de http://www.digitaliapublishing. com/a/4024/ensayos-profanos

Franco, F. (2012). La Población dominicana: razas, clases, mestizaje y migraciones. Editora Universitaria. UASD, Ed.

García García, C. (2012). Modernidad y Blanquitud de Bolívar Echeverría. Revista Mexicana de Orientación Educativa, 9(22), 64-65. Recuperado de http://pepsic.bvsalud.org/scielo.php?script $=$ sci_arttext $\&$ pid $=S 1665-752720120$ 00100012

García Godoy, F. (2018). Obras casi completas (A. Blanco Díaz, Ed.; Vol. 6). Archivo General de la Nación. Recuperado de https://catalog. princeton.edu/catalog/10790074

Mateo, A. L. (1993). Mito y Cultura en la Era de Trujillo. Librería La Trinitaria.

Mena, M. D. (2007, March 12). Pedro Andrés Pérez Cabral y La comunidad mulata, 40 años después. Areito, Hoy Digital. Recuperado de https://hoy.com.do/pedro-andres-perez-cabral-y-\%C2\%93la-comunidad-mulata\%C2\%94-40-anos-despues/

Moscoso Puello, F. (1936, January 18). De la Odisea de la Hispaniola. La Opinión.

Moscoso Puello, F. (2000). Cartas a Evelina. Editora Cole.

Moscoso Puello, F. (2004). Cañas y Bueyes. Abc.

Moscoso Puello, F. (2015). Navarijo (2da reimpresión). Sociedad Dominicana de Bibliófilos.

North, S. M. (1986). Writing in a Philosophy Class: Three Case Studies on JSTOR. Research in the Teaching of English, 3(20), 225-262. Recuperado de https://www.jstor.org/stable/ 40171082? read-now=1\&seq=7\#page_scan_ tab_contents
Pérez Cabral, P. A. (1976). La Comunidad mulata. El caso sociopolitico de la República Dominicana. Gráfica Americana. Recuperado de http:// www.cielonaranja.com/comunidadmulata.pdf

Pitkowski, E. F., y Gamarra, J. V. (2009). El uso de los corpus lingüísticos como herramienta pedagógica para la enseñanza y aprendizaje de ELE. Tinkuy. Boletin de Investigación y Debate, 11, 21-51. Recuperado de https://www. researchgate.net/publication/47548471_El_ uso_de_los_corpus_linguisticos_como_herramienta_pedagogica_para_la_ensenanza_y_ aprendizaje_de_ELE/citation/download

Portocarrero, G. (2013). La utopía del blanqueamiento y la lucha por el mestizaje. En Hegemonía cultural y políticas de la diferencia (pp. 165-200). CLACSO. Recuperado de http:// www.mgblog.net/8260/chica-terra/claudia-

Ricoeur, P. (1987). Tiempo y Narración. I. Configuración del tiempo en el relato histórico. Cristiandad.

Ricoeur, P. (1996a). Sí mismo como otro. Siglo XXI. Ricoeur, P. (1996b). Tiempo y Narración III. El Tiempo Narrado. Fondo de Cultura Económica.

Ricoeur, P. (1999). La Identidad Narrativa. En Historia y Narratividad (pp. 215-230). Paidós.

Ricoeur, P. (2002). Del Texto a la Acción. Ensayos de Hermenéutica II. Fondo de Cultura Económica.

Rodríguez, N. (2004). El Rasero de la raza en la ensayística dominicana. Revista Iberoamericana, $L X X, 473-490$.

Sánchez Escobar, Á. F. (2001). El método hermenéutico aplicado a un nuevo canon: hacia la autorización de la producción escrita de los estudiantes de inglés. CAUCE, Revista de Filología y Su Didáctica, 24, 295-323. Recuperado de https://cvc.cervantes.es/literatura/cauce/ pdf/cauce24/cauce24_18.pdf

Santos Cueto, R. D. (2017). Filosofía y lenguaje en Paul Ricoeur: la lectura y la escritura. Revista de Filosofía, 16(2), 39-63. Recuperado de https://doi.org/0000-0001-6595-1892 
Sarmiento, D. F. (2007). Conflicto y armonias de razas en América (Vol. 1). Biblioteca Quiroga Sarmiento. Recuperado de http://www.cervantesvirtual.com/obra/conflicto-y-armonias-derazas-en-america--0/

Silié,R. (1989).Esclavitudy prejuiciodecolorenSanto Domingo. Boletin de Antropología Americana, 20, 163-170. Recuperado de https://www. jstor.org/stable/40977500? read-now=1 \&refreqid=excelsior $\% 3 \mathrm{Ab} 5 \mathrm{cc} 0 \mathrm{~b} 6 \mathrm{a} 5 \mathrm{fa} 18 \mathrm{be} 5 \mathrm{~cd}$ 94e262138fe509\&seq=1\#page_scan_tab_ contents
Tinoco Guerra,A.E. (2017). Deundeterminismo a otro: 2500 años de prejuicios sociales. Universidad de Zulia. Recuperado de https://bonga.unisimon. edu.co/bitstream/handle/20.500.12442/2102/ Determinismo.pdf? sequence $=1$ \&isAllowed $=\mathrm{y}$ Valderrama, P. (1986). El carácter nacional y la psicología de los pueblos en América Latina. Revista Latinoamericana de Psicología, 18(1), 87-107. Recuperado de https://www.redalyc. org/articulo.oa?id=80518106 